\title{
Azomesogens with a heterocyclic moiety ${ }^{\dagger}$
}

\author{
JAYRANG S DAVE and MEERA MENON* \\ Department of Applied Chemistry, Faculty of Technology and Engineering, MS University of Baroda, \\ Baroda 390 001, India
}

\begin{abstract}
Azobenzene derivatives were among the first ten liquid crystalline compounds. But there have been no detailed investigations on azomesogens consisting of a heterocyclic moiety. Twelve different azo compounds have been condensed with nicotinic acid to evaluate the effect of variation of terminal group on the monosubstituted pyridine system. The relative thermal stabilities and the variation in the mesomorphic characteristics have also been studied.
\end{abstract}

Keywords. Azomesogens; heterocyclic; terminal; polarizable; group efficiency order.

\section{Introduction}

There have been a variety of compounds reported with liquid crystalline properties, but heterocyclic moieties (Nash and Gray 1974; Brown et al 1994) are less explored, compared to homocyclic moieties. The hetero atom in a pyridine ring system is known to behave in many respects to an aromatic nitro group (Mosher 1950).

In the present study we have investigated the mesomorphic characteristics of several structurally related pyridine derivatives in which the nature of terminal moiety is changed and an attempt has been made to relate the changes observed in mesophase thermal stability to these changes in moiety.

\section{Experimental}

The compounds were prepared by reported methods.

\subsection{4-Substituted-4'-hydroxyazobenzenes}

The higher 4- $n$-alkoxy azobenzene derivatives were synthesized by reported method (SCI, B.P.; Furniss et al 1994).

\subsection{Nicotinoyl chloride}

\subsection{4(4'-Substituted phenyl azophenyl)-3"-nicotinates}

The above compound was synthesized by the following method (Dave and Dhake 1993). 0.01 mole of nicotinoyl chloride, taken in $20 \mathrm{ml}$ benzene was added to a solution

\footnotetext{
*Author for correspondence

${ }^{\dagger}$ Paper presented at the 5th IUMRS ICA98, October 1998, Bangalore
}

of 0.01 mole of respective 4-substituted-4'-hydroxyazobenzene in $30 \mathrm{ml}$ benzene and $10 \mathrm{ml}$ triethylamine in cold condition. The mixture was refluxed for $6 \mathrm{~h}$ with constant stirring. It was cooled and acidified with $1: 1$ cold $\mathrm{HCl}$. The product obtained was then recrystallized from alcohol.

The elemental analysis of all the compounds confirm with the calculated ones. The transition temperatures and mesomorphic characteristics were studied under Leitz Laborlux polarizing microscope fitted with a heating stage.

The FTIR spectroscopic data of few of the compounds were obtained on a Perkin-Elmer FTIR spectrometer. IR $\left(\mathrm{cm}^{-1}\right)$ for the butoxy derivative are 1679 (-COOstretch), $1600(-\mathrm{N}=\mathrm{N}-$ stretch), 1248 (alkyl aryl ether stretch) and 1474 (aromatic C-C stretch).

\section{Results and discussion}

Table 1 summarizes the transition temperatures of the compounds.

The common structural features of the compounds are that they consist of two phenyl rings and a pyridinyl ring linked through azo and ester central linkages; with different terminal groups at one end (figure 1).

It is observed that the lower $n$-alkoxy derivatives i.e. from methoxy to $n$-butoxy members, are nematogens and exhibit odd-even effect in their $N-I$ transition temperature curve as explained by Gray and Winsor (1974). The higher $n$-alkoxy derivatives viz. $n$-decyloxy and $n$-dodecyloxy, exhibit an additional smectic $\mathrm{C}$ phase along with nematic mesophase, which can be attributed to the increase in alkoxy chain length at one end. The compounds with $-\mathrm{CH}_{3},-\mathrm{NO}_{2},-\mathrm{Cl}$ and $-\mathrm{Br}$ end groups exhibit only nematic phases, with the mesophase range being least for the compound having $-\mathrm{CH}_{3}$ group at the terminal position and the same being maximum when the $-\mathrm{CH}_{3}$ group is replaced by $-\mathrm{NO}_{2}$ moiety. Methyl group is mildly 
Table 1. Transition temperatures of $4\left(4^{\prime}\right.$-substituted)phenyl azo phenyl-3"-nicotinates.

\begin{tabular}{lccc}
\hline & \multicolumn{3}{c}{ Transition temperatures $\left({ }^{\circ} \mathrm{C}\right)$} \\
\cline { 2 - 4 }$R$-group & Smectic & Nematic & Isotropic \\
\hline$-\mathrm{OCH}_{3}$ & - & 145 & 209 \\
$-\mathrm{OC}_{2} \mathrm{H}_{5}$ & - & 140 & 212 \\
$-\mathrm{OC}_{3} \mathrm{H}_{7}$ & - & 131 & 205 \\
$-\mathrm{OC}_{4} \mathrm{H}_{9}$ & - & 120 & 208 \\
$-\mathrm{OC}_{10} \mathrm{H}_{21}$ & $92^{\dagger}$ & 165 & 180 \\
$-\mathrm{OC}_{12} \mathrm{H}_{25}$ & $95^{\dagger}$ & 172 & 176 \\
$-\mathrm{CH}_{3}$ & - & 136 & 139 \\
$-\mathrm{NO}_{2}$ & - & 206 & 240 \\
$-\mathrm{Cl}^{-}$ & - & 165 & 178 \\
$-\mathrm{Br}$ & - & 172 & 179 \\
$-\mathrm{COCH}_{3}$ & $164^{*}$ & 174 & 225 \\
$-\mathrm{COCH}_{2} \mathrm{CH}_{3}$ & $158^{*}$ & 180 & 230 \\
\hline
\end{tabular}

The compound exhibits * smectic A phase, ${ }^{\dagger}$ smectic C phase

polar, while nitro group will endow the molecules with high polarity, greater terminal attractions and hence higher nematic mesophase range (Gray and Harrison 1971). $-\mathrm{Br}$ and $-\mathrm{Cl}$ groups are also effective polaritywise, but as bromo moiety is somewhat broader than chloro group, it should explain the lower phase range of the bromo compound. The compounds with more polarizable terminal groups like $-\mathrm{COCH}_{3}$ and $-\mathrm{COCH}_{2} \mathrm{CH}_{3}$, exhibit nematic as well as smectic $\mathrm{A}$ mesophases. Compound with propionyl terminal group exhibits higher smectic mesophase range compared to that of the compound with acetyl end group which can be attributed to the additional methylene unit in the propionyl derivative. The group efficiency order for the nematic phase thermal stability can be derived for the compounds as under.

$$
\begin{aligned}
& -\mathrm{NO}_{2}>-\mathrm{COCH}_{2} \mathrm{CH}_{3}>-\mathrm{COCH}_{3}>-\mathrm{OC}_{2} \mathrm{H}_{5}> \\
& n-\mathrm{OC}_{4} \mathrm{H}_{9}>n-\mathrm{OC}_{3} \mathrm{H}_{7}=-\mathrm{OCH}_{3}>-\mathrm{OC}_{10} \mathrm{H}_{21}> \\
& -\mathrm{OC}_{12} \mathrm{H}_{25}>-\mathrm{Cl}>-\mathrm{Br}>-\mathrm{CH}_{3} .
\end{aligned}
$$

It agrees well with the nematic group efficiency order obtained by Gray for pure mesogenic systems (Gray and Winsor 1974).

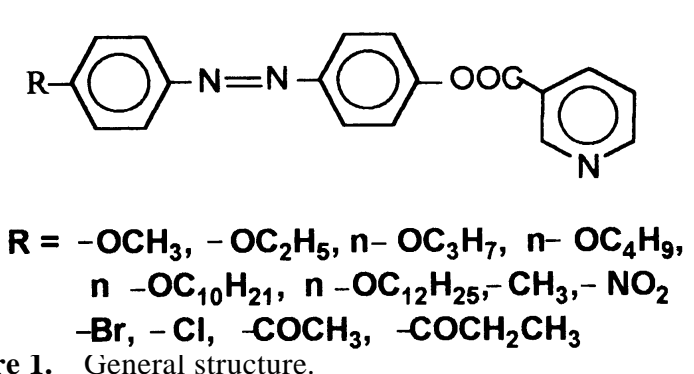

Figure 1. General structure.

It is observed that the compounds with ketonic end groups exhibit smectic A phase compared to derivatives with $n$-alkoxy terminal moieties which exhibit the smectic C phase.

\section{Conclusion}

It is seen that the effect of $R$-terminal group on account of varying polarizability, polarity and $n$-alkoxy chain length contributes to the changes observed in transitions, mesophase temperature range and mesophase textures.

\section{References}

Brown J W, Hurst D T and O’Donovan J P 1994 Liq. Cryst. 17 689

Dave Jayrang S and Dhake K P 1993 J. Indian Chem. Soc. 70591

Furniss B S, Hannaford A J, Smith P W G and Tatchell A R (eds) 1994 Vogel's textbook of practical organic chemistry (England: Longman Singapore Publishers Pvt Ltd) pp 949950

Gray G W and Harrison J K 1971 Mol. Cryst. Liq. Cryst. 1337

Gray G W and Winsor P A 1974 Liquid crystals and plastic crystals (Chichester: England Ellis Horwood Ltd) Vol. 1, pp 116-122

Mosher H S 1950 Heterocyclic compounds (ed.) R C Elderfield (New York: Wiley) Vol. 1, p. 97

Nash J A and Gray G W 1974 Mol. Cryst. Liq. Cryst. 25299

SCI, B P Society of Chem Industry, Basle, 447561 eg 4 